\title{
miRNAs in decidual NK cells: regulators worthy of attention during pregnancy
}

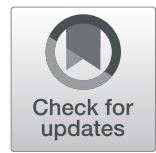

Liman $\mathrm{Li}^{\dagger}$, Ting Feng ${ }^{\dagger}$, Weijie Zhou, Yuan Liu and Hong Li ${ }^{*}$

\begin{abstract}
The critical immune effectors, including T, B, and natural killer (NK) cells, dendritic cells, and macrophages participate in regulating immune responses during pregnancy. Among these immune cells, decidual NK (dNK) cells are involved in key placental development processes at the maternal-fetal interface, such as uterine spiral artery remodeling, trophoblast invasion, and decidualization. Mechanistically, dNK cells significantly influence pregnancy outcome by secreting cytokines, chemokines, and angiogenic mediators and by their interactions with trophoblasts and other decidual cells. MicroRNAs (miRNAs) are small non-coding RNA molecules that participate in the initiation and progression of human diseases. Although the functions of circulating miRNAs in pathological mechanism has been extensively studied, the regulatory roles of miRNAs in NK cells, especially in dNK cells, have been rarely reported. In this review, we analyze the effects of miRNA regulations of dNK cell functions on the immune system during gestation. We discuss aberrant expressions of certain miRNAs in dNK cells that may lead to pathological consequences, such as recurrent pregnancy loss (RPL). Interestingly, miRNA expression patterns are also different between dNK cells and peripheral NK (pNK) cells, and pNK cells in the first- and third-trimester of gestation. The dysregulation of miRNA plays a pivotal regulatory role in driving immune functions of dNK and pNK cells. Further understanding of the molecular mechanisms of miRNAs in dNK cells may provide new insights into the development of therapeutics to prevent pregnancy failure.
\end{abstract}

Keywords: Decidual NK cells, miRNAs, Immune regulation, Pregnancy

\section{Introduction}

A delicate immune balance is crucial for maintaining pregnancy, and disruption of this balance can lead to certain pregnancy complications, such as recurrent pregnancy loss (RPL), pre-eclampsia (PE), and fetal growth retardation (FGR) [1]. The maternal-fetal interface consists of various immune cells, decidual stromal cells, and trophoblast cells. These fetal and maternal cells can contact each other to maintain immunologic tolerance and normal fetal growth [2]. The presence of innate and adaptive immune cells is one of the characteristics of early pregnancy [3, 4], including approximately

\footnotetext{
*Correspondence: lihonghx@scu.edu.cn

${ }^{\dagger}$ Liman Li and Ting Feng contributed equally to this work.

Center of Translational Medicine, Key Laboratory of Birth Defects and Related Diseases of Women and Children of Ministry of Education, West China

Second University Hospital, Sichuan University, Chengdu, China
}

$70 \%$ of decidual NK (dNK) cells [5], $20-30 \%$ of macrophages [6], $1.7 \%$ of dendritic cells [7], and $3-10 \%$ of $\mathrm{T}$ cells (including Treg cells and $\gamma \delta \mathrm{T}$ cells) [8]. Advances in understanding the mechanisms by which NK cells modulate the immune system during pregnancy have increased in recent years [9-12]. Evidence also supports that microRNAs (miRNAs) are involved in immune cell development, which may be selectively regulating the placental development as well as subsequent conceptus viability [13]. In this review, we highlight the roles of dNK cells in pregnancy and the complicated interplays with miRNA regulatory networks. A better understanding of the miRNA regulation of NK cells in pregnant women and their functional specificity could open a new avenue for translational applications in precision medicine and

(c) The Author(s). 2021 Open Access This article is licensed under a Creative Commons Attribution 4.0 International License, which permits use, sharing, adaptation, distribution and reproduction in any medium or format, as long as you give appropriate credit to the original author(s) and the source, provide a link to the Creative Commons licence, and indicate if changes were made. The images or other third party material in this article are included in the article's Creative Commons licence, unless indicated otherwise in a credit line to the material. If material is not included in the article's Creative Commons licence and your intended use is not permitted by statutory regulation or exceeds the permitted use, you will need to obtain permission directly from the copyright holder. To view a copy of this licence, visit http://creativecommons.org/licenses/by/4.0/ The Creative Commons Public Domain Dedication waiver (http://creativecommons.org/publicdomain/zero/1.0/) applies to the data made available in this article, unless otherwise stated in a credit line to the data. 
miRNA-based therapeutic tools to protect the fetus and the mother.

\section{dNK cells in pregnancy}

A large number of immune cells, including macrophages, $\mathrm{T}$ cells, dendritic cells, $\gamma \delta \mathrm{T}$ cells, NK cells are present in decidua during early pregnancy, and the three major leukocyte subsets are NK cells, cluster of differentiation (CD) 14+ myelomonocytic cells, and T cells [14]. Among them, dNK cells make remarkable contributions to spiral artery remodeling, trophoblast invasion processes, prevention of pathogenic invasion of fetal placenta, as well as decidualization, which play critical roles in pregnancy success (Fig. 1). Decidual NK cells are a unique tissue-resident subpopulation and the most abundant cell type (accounting for around $70 \%$ of decidual leucocytes) in first trimester of gestation [15]. Several studies have proposed that $\mathrm{dNK}$ cells originate from the migration of pNK cells or the differentiation of hematopoietic precursors CD34+stem cells $[16,17]$. Decidual NK cells are characterized by the $\mathrm{CD} 56^{\text {bright }} \mathrm{CD} 16^{-}$surface phenotype with considerable immune regulatory cytokine production and high expressions of killer cell Ig-like receptors (KIRs) that are distinct from pNK cells and other tissue-resident NK subsets [18]. There is evidence for dNK cells' abilities to produce a variety of cytokines, chemokines, and angiogenic mediators such as interferon (IFN)- $\gamma$, tumor necrosis factor (TNF)- $\alpha$, interleukin (IL)-8, interferon gamma-inducible protein (IP)-10, and vascular endothelial growth factor (VEGF) that participate in immunomodulation during pregnancy $[19,20]$.

\section{Interactions of dNK cells/other decidual cells}

The interactions between $\mathrm{dNK}$ and other decidual cells play key roles in maintaining maternal-fetal immune tolerance. For instance, CXCL16 derived from trophoblasts leads to M2 macrophage polarization that in turn modulates the killing ability of dNK cells [21]. Decidual NK cells are closely connected with decidual myelomonocytic CD14+ (dCD14+) cells. Following interaction with dNK cells, dCD14 + cells are capable of inducing regulatory $\mathrm{T}$ cells (Treg) cells. Mechanistically, IFN- $\gamma$ secreted from dNK cells induces indoleamine 2,3-dioxygenase (IDO) up-regulation in CD14+cells. In turn, IDO can induce the Treg cells by generating the tryptophan catabolite L-kinurenine. Interestingly, only the interaction between $\mathrm{dNK}$ and $\mathrm{dCD} 14+$ cells lead to Treg cell induction, whereas other coculture combinations such as NK and CD14 + cells isolated from peripheral blood are ineffective [22].

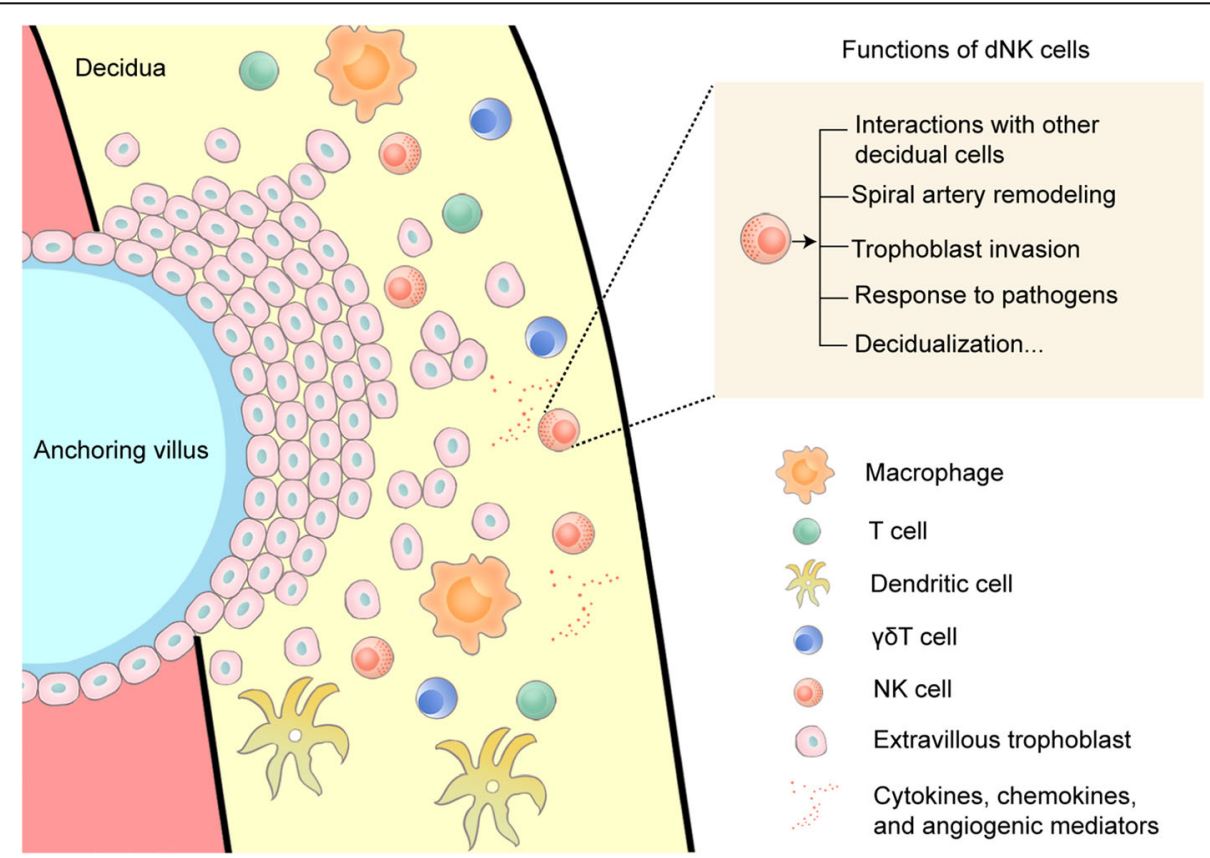

Fig. 1 Diagram illustrating the immune cells at maternal-fetal interface. A large number of immune cells, including macrophages, T cells, dendritic cells, $\gamma \delta T$ cells, NK cells are present in decidua. They have capabilities of secreting cytokines, chemokines, and angiogenic mediators, and establishing interactions with other decidual cells. These functional immune cells are essential for maintaining the immune balance at maternal-fetal interface. Among them, decidual NK cells make remarkable contributions to spiral artery remodeling, trophoblast invasion processes, prevention of pathogenic invasion of fetal placenta, as well as decidualization, which play indispensable roles in pregnancy success. dNK cell, Decidual NK cell 


\section{dNK cells control spiral artery remodeling}

Uterine spiral artery remodeling is one of the most important physiological changes in pregnancy. Pregnancy complications such as PE, FGR, and RPL are linked with impaired spiral artery remodeling [23, 24]. Successful uterine spiral artery remodeling depends on a series of sequential steps, including vascular dilatation, endothelial cell swelling, destruction of the vascular smooth muscle cell (VSMC) layer, and subsequent fibrinoid matrix deposition and invasion of extra-villous cytotrophoblasts. It has been shown that this process is regulated by the massive infiltration of maternal immune cells in the decidua $[25,26]$. Decidual NK cells can secrete IL-8, IFN- $\gamma$, and TNF- $\alpha$ to initiate the destabilization of vascular structures and spiral artery transformation before extra-villous trophoblast (EVT) interaction $[27,28]$. Decidual NK cell-derived IFN- $\gamma$ could induce the up-regulation of lncMEG3 expression in VSMCs. Decidual NK cell/IFN- $\gamma$ treatment and lncMEG3 overexpression inhibit VSMC proliferation and stimulate VSMC migration and apoptosis [29]. Furthermore, dNK cells also affect VSMC biology by secreting angiopoietin (ANG)-1and ANG-2, which promote VSMC to migrate into the stroma surrounding remodeling spiral arteries where they undergo apoptosis and are phagocytosed by resident macrophages [24].

\section{dNK cells regulate trophoblast invasion}

Balanced EVT invasion regulation is key to gestation success [30]. Deficiency of invaded trophoblastic cells is the one of main causes of dysfunctional placentas. Inadequate motility of trophoblastic cells leads to abnormal remodeling of spiral arteries and disrupts material exchange between fetus and mother, thus causing a series of pregnancy-related disorders [31, 32]. Earlier study has revealed that trophoblast migration and invasion are correlated with the enhanced ability of $\mathrm{dNK}$ cells to produce IL-8 and IP-10, which bind to C-X-C motif chemokine receptor 1(CXCR1) and CXCR3 expressed by invasive EVT, respectively [33]. Additionally, dNK cells could promote trophoblast invasion by producing hepatocyte growth factor (HGF) and inducing trophoblast differentiation toward the endothelial phenotype by the secretion of VEGF-C and HGF [34]. In PE pregnancies, dNK cells exhibit a reduced promotion effect on first trimester trophoblast invasion and migration when compared to normal controls. In small-for-gestational-age (SGA) pregnancies, dNK cells show impairments in proliferation, migration, invasion, and tube formation of trophoblast cells or vascular endothelial cells compared to those in appropriate-forgestational-age (AGA) pregnancies [35].

\section{dNK cells response to pathogens}

Threatening pathogens can jeopardize the function of the maternal-fetal interface and spread to the fetus, with negative consequences. For instance, infections by TORCH pathogens can result in fetal growth retardation or death, organ injury, or other sequelae [5, 36]. Remarkably, dNK cells are able to infiltrate human cytomegalovirus (HCMV)-infected tissue and co-localize with infected cells. dNK cells become cytotoxic effectors when they are exposed to HCMV-infected cells and the killer cell lectin-like receptor $\mathrm{K} 1$ (also known as NKG2D), CD94/NKG2C, or 2E activating receptors participate in the acquired cytotoxic function. Activation of dNK cells could increase their abilities to respond to placental HCMV infection and limit the subsequent virusinduced placental pathology [37]. In addition, dNK cells can release IFN- $\gamma$ to limit HIV replication in decidual macrophages and directly transfer granulysin (GNLY) to fetal cells by nanotubes, killing intracellular Listeria monocytogenes without killing the host cell [38, 39]. Taken together, dNK cells may reduce bacterial loads at the maternal-fetal interface as a result of their cytotoxic functions. More importantly, dNK cells can provide the immune defense that protects the target cells and is compatible with maintaining maternal-fetal immune tolerance. However, as new viruses emerge, such as coronavirus disease 2019 (COVID-19), which is associated with a high incidence of severe maternal and neonatal complications [40], further studies are urgently needed for a better understanding of the roles of dNK cells in protecting the mother and the fetus against new bacterial, fungal, and parasitic pathogens.

\section{dNK cells contribute to decidualization}

Decidualization is necessary for normal implantation of the blastocyst [41]. Previous studies have exhibited that the absolute number as well as the percentage of uterine NK (uNK) in uterine immune cells are significantly decreased in endometrium of estrous mice, compared to pregnant mice. This result indicates that decidualization is accompanied by NK cell enrichment [42]. Furthermore, autocrine/paracrine factors are linked to endometrial decidualization, like parathyroid hormone-like hormone (PTHLH), cytokines, IL-11, and activin A [43, 44]. As for dNK cells, with the transformation of endometrial stromal cells (ESCs) into decidual stromal cells (DSCs) during decidualization, IL-24 derived from DSCs can induce CD56 $6^{\text {dim }}$ uNK to differentiate into CD $56^{\text {bright }} \mathrm{CD} 16^{-} \mathrm{dNK}$ with high immunomodulation and angiogenic activities, and low cytotoxic activity that benefits normal pregnancy [45]. Interestingly, dNK cells can secrete IL-25 facilitating the decidualization of ESCs [46], which have a positive feedback effect on maternal-fetal interface.

\section{miRNA basics}

miRNAs are a class of $\sim 22$ nt non-coding RNAs that negatively regulate gene expression through directly 
binding the 3'UTR of mRNA targets [47]. The miRNA class is found in all eukaryotic cells and some viruses. Research in the past few years reported that miRNAs have potential as biomarkers for the early detection and therapeutic targeting of diseases as well as acting as important regulatory elements in healthy and cancerous tissues $[48,49]$. Of note, miRNAs can be packaged within extracellular vesicles including exosomes and microvesicles, and these vesicles contain numerous miRNAs that transfer between cells, thereby establishing intercellular communication [50].

\section{Differentially Expressed miRNAs (DEMs) in dNK and pNK cells during pregnancy}

DEMs in pNK cells derived from different pregnancy time points

A previous study [51] performed real-time PCR-based arrays to explore the levels of 756 miRNAs in pNK cells at different time points (first, second, and third trimester and post-delivery) in pregnancy. The researchers provided a comparison of miRNA expression profiles and demonstrated a total of 25 miRNAs are significantly up-regulated and only 1 miRNA (miR-7-2-3p) is significantly downregulated in pNK cells in the third trimester compared to the first trimester. Among these dysregulated miRNAs, miR-517a-3p and miR-518b, two placenta-derived miRNAs [chromosome 19 miRNA cluster (C19MC) miRNAs] are significantly up-regulated in the third trimester and down-regulated at 4 days following delivery, suggesting that the transfer of placental miRNAs into maternal pNK cells might occur during pregnancy. Researchers hypothesized these interactions are possibly mediated via exosomes [52].

\section{DEMs in dNK cells and matched pNK cells}

Furthermore, another study [53] compared the miRNA expression pattern in dNK cells and their matched pNK cells. Results show there are 86 miRNAs significantly expressed in dNK and pNK cells samples. There are 48 miRNAs commonly expressed in both $\mathrm{dNK}$ and pNK cells but only 5 miRNAs expressed in dNK and pNK cells at similar levels. A great majority of miRNAs display differential expressions in the two NK cell populations. Of note, there are 28 up-regulated and 15 downregulated miRNAs in dNK cells compared to matched pNK cells, and 36 exclusively expressed miRNAs in dNK cells whereas there are only 2 exclusively expressed miRNAs in pNK cells.

Validation analysis via qPCR revealed that miR-214 and miR-10b are expressed only in dNK cells, while miR-200a-3p is expressed only in pNK cells. For the commonly expressed miRNAs, miR-130b-3p, miR-125a$5 p$, miR-212-3p, and miR-454 are up-regulated while
miR-210-3p and miR-132 are down-regulated in $\mathrm{dNK}$ cells compared to pNK cells in all samples.

The differential miRNA expression patterns in dNK and pNK cells might be associated with the acquisition of special phenotypes of NK cell subsets and the modulation of their unique functions. However, investigations into the importance of these mechanisms are still at an early stage. Large follow-up studies are warranted to explore these regulatory networks.

\section{miRNA regulation of $d N K$ cell immune function during pregnancy}

NK cells develop from hematopoietic stem cells and mature after experiencing intermediate states such as NK precursor cells (NKP) and immature NK cells (iNK) [54]. Developing NK cells exhibit a dynamic miRNA expression profile that is substantially different from that of mature NK cells. miRNAs have been highlighted as direct modulators of NK cell fate [55]. However, the underlying, relevant pathways triggering immune responses in pregnancy remain insufficiently understood. Exciting discoveries during the past 10 years have revealed the direct interplay between dysregulated miRNAs in NK cells and gestation outcome (Fig. 2).

\section{Regulation of dNK cell activation}

miR-30e has been implicated in the pathogenesis of a variety of human diseases, such as bladder cancer, breast cancer, and cardiac fibrosis [56-58]. Recently, investigators demonstrated the effects of miR-30e on regulating the functions of $\mathrm{pNK}$ and $\mathrm{dNK}$ cells at maternal-fetal interface [59]. They found the expression of miR-30e is decreased in both peripheral blood and decidual tissues in RPL patients, suggesting that the alteration of miR-30e may be related to the pathogenesis of RPL. Further results show that miR-30e is downregulated and its downstream target gene, PRF1 (Perforin 1), is up-regulated in the activated $\mathrm{pNK}$ and $\mathrm{dNK}$ cells (activated by IFN- $\alpha$ ), indicating that miR-30e may be associated with the activation of NK cells by negatively regulating PRF1.

\section{Regulation of dNK cell cytotoxicity}

Furthermore, in pNK and dNK cells, the expression of NKp44, an activating receptor, is reduced and the expression of killer cell immunoglobulin-like receptor, two Ig domains and long cytoplasmic tail 1 (KIR2DL1), an inhibitory receptor, is elevated in the miR-30e mimics group, while NKp44 is increased and KIR2DL1 is inhibited in the miR-30e inhibitors group [59]. NKp44 is responsible for the increase in killing of cell lines and the release of cytotoxic granules [60]. In addition, NKp44 on $\mathrm{dNK}$ cells is critical for the tolerance of pregnancies in the uterus $[61,62]$. KIR2DL1 is a crucial member of KIR 


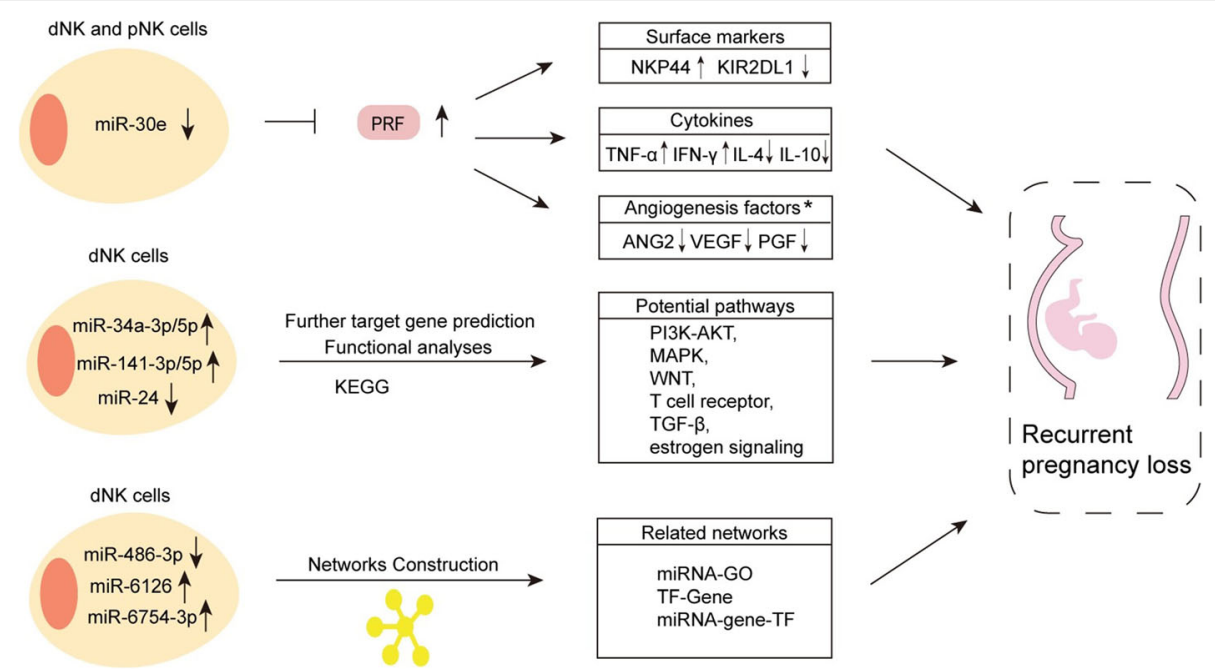

Fig. 2 Differentially expressed miRNAs in dNK cells may be associated with RPL. miR-30e, miR-34a-3p/5p, miR-141-3p/5p, miR-24, miR-486-3p, miR-6126 and miR-6754-3p are dysregulated in dNK and pNK cells of RPL patients. These miRNAs mediate their downstream immune-related proteins and regulatory pathways which might be associated with RPL. RPL, Recurrent pregnancy loss; dNK cell, Decidual NK cell; pNK cell, Peripheral NK cell; PRF, Perforin 1. * These immune-related proteins only change in dNK cells

family that could deliver several signals that inhibit cytotoxicity of NK cells [63]. Overall, miR-30e might affect NK cell cytotoxicity by regulating the expressions of NKp44 and KIR2DL1.

\section{Regulation of dNK cell cytokine secretion}

One of main functions of NK cells is the production of cytokines [64]. TNF- $\alpha$, IFN- $\gamma$, IL-4, and IL-10 are spontaneously released by pNK and dNK cells and could be important for maintaining a successful pregnancy [65, 66]. In both pNK and dNK cells, the miR-30e mimics group showed higher mRNA and protein expression of IL-10 and IL-4 compared to the negative control group, and the miR-30e inhibitors group showed lower mRNA and protein expressions of IL-10 and IL-4 compared to the negative control group. The miR-30e mimics group had decreased mRNA and protein expression of TNF- $\alpha$ and IFN- $\gamma$, while the miR-30e inhibitors group had elevated mRNA and protein expressions of TNF- $\alpha$ and IFN- $\gamma$ [59]. These findings suggest that miR-30e in NK cells can enhance the release of IL- 4 and IL-10 while repressing the production of TNF- $\alpha$ and IFN- $\gamma$.

ANG-2 [67], VEGF [68], and placental growth factor (PGF) [69] have recently been studied for their roles in the development of the placenta and fetus. Women with low VEGF and PGF level are believed to be at higher risk of RPL and SGA $[68,70]$. The discovery of miRNAs in dNK cells could potentially affect growth factors production at maternal-fetal interface. For example, in dNK cells, ELISA and qPCR results show that both concentrations and mRNA expression of ANG-2, VEGF, and PGF are increased in the miR-30e mimics group while decreased in the miR-30e inhibitors group [59]. This study illustrates mechanisms by which decreased miR30e expression in dNK cells may directly affect their functions of promoting fetal development. Specific targeting of miR-30e in dNK cells might contribute to the development of novel intervention strategies (therapies that use miRNA mimetics and anti-miRNA oligonucleotides), aiming at regulating dNK cell induction in RPL and SGA.

\section{Involvements of functional pathways}

A previous study [71] have detected the expression levels of miR-34a, miR-24, miR-155, miR-125a, miR-125b, and miR-141 in dNK cells derived from RPL patients and control groups via qPCR. The results showed that miR-24 is down-regulated while other 5 miRNAs are up-regulated in the RPL group suggesting that these miRNAs may play indispensable roles at the maternal-fetal interface. Furthermore, miR-34a, miR-141, and miR-24 are subjected to target gene prediction and pathway analysis. KEGG analysis of the predicted targets of these 3 miRNAs reveal 140 pathways, including PI3K-AKT, MAPK, WNT, T-cell receptor, TGF- $\beta$, and estrogen signaling pathways. These canonical pathways have been identified to affect the development and function of NK cells during pregnancy. For example, activated PI3K-AKT signaling pathway in dNK cells can increase the GzmB, Perforin, IFN- $\gamma$, and IL10 production [72], uncovering miRNA in NK cells may mediate immune mechanisms in gestation. Further research has been conducted with miRNA microarrays to explore miRNA expression profiling in $\mathrm{dNK}$ cells derived from RPL patients and healthy controls [73]. 
The researchers have identified 50 differentially expressed miRNAs, including 49 up-regulated and 1 down-regulated miRNA in the RPL group (For example, miR-486-3p, miR-6126, and miR-6754-3p). The only down-regulated one is miR-486-3p which has been proven to display dysregulated expression in PE patients compared with the control group [74]. The findings have also exhibited miRNA-GO, TF-Gene, and miRNA-gene-TF networks that may be associated with regulatory mechanisms of RPL. Importantly, miR3620-5p is present in all three networks above, indicating it might be critical in regulating $\mathrm{dNK}$ cell function at the maternal-fetal interface.

\section{Future directions}

Currently, a clinical need exists for predictive biomarkers of pregnancy complications, such as RPL [75]. The number of NK cells has already become a clinical reference index for RPL [76], and several circulating miRNAs are also known to be differentially expressed in RPL patients when compared with healthy individuals, acting as potential biomarker candidates [77, 78]. But whether differentially expressed miRNAs in NK cells can be able to more accurately discern normal individuals from those with pregnancy related disorders should be revealed in more in-depth studies. In addition, whether these dysregulated miRNAs in NK cells identify pregnant women who are at risk of pregnancy complications has substantial value for alleviating the impact of gestational diseases. On the other hand, immunosuppressant interventions are commonly used to treat RPL in recent years $[79,80]$. It is still unclear that whether the levels of miRNAs in dNK cells could be affected by clinical interventions, which can monitor the effects of interventions on pregnancy complications. For in vivo applications, the potential for miRNA-targeted therapeutics has been indicated [81, 82], and safe miRNA-targeted drugs are attracting much attention from researchers and hold great promise for clinical treatments of pregnancy related diseases.

Lastly and importantly, tre existing literature on $\mathrm{dNK}$ cell molecule regulation is very limited; most report on only the expression levels of miRNAs [53, 59, 83], and few are in-depth reports focused on the basic mechanisms of miRNA function. This lack may be related to the difficulty in purifying enough primary $\mathrm{dNK}$ cells to meet the requirements of deep sequencing. It is also challenging to conduct gene knockout experiments in primary dNK cells [38]. Additionally, many small molecules including circular RNAs and methylation modifiers (such as N6-methyladenosine and 5-hydroxymethylcytosine) have not been examined in dNK cells. Whether the RNA modifications $[84,85]$ in dNK cells and pNK cells regulate biological immune functions during pregnancy is worth exploring in the future.

There are functional miRNAs in ESCs [86] (such as miR-149 [87], miR-181a [88], miR-21 [89], and miR542-3p [90]), influencing the endometrial decidualization process. Regulatory miRNAs in trophoblast cells also contribute to their proliferation, migration, and invasion (such as miR-210 [91], miR-126-3p [92], and miR-23a [93]) during pregnancy. Of note, exosomes play crucial roles in the mediation of cell-to-cell communication at maternal-fetal interface $[94,95]$, and it is worth exploring that whether above functional miRNAs can be transferred into dNK cells by ESCs/trophoblasts-derived exosomes in pregnancy related disorders, inducing dysfunctions of dNK cells and impairing immune system

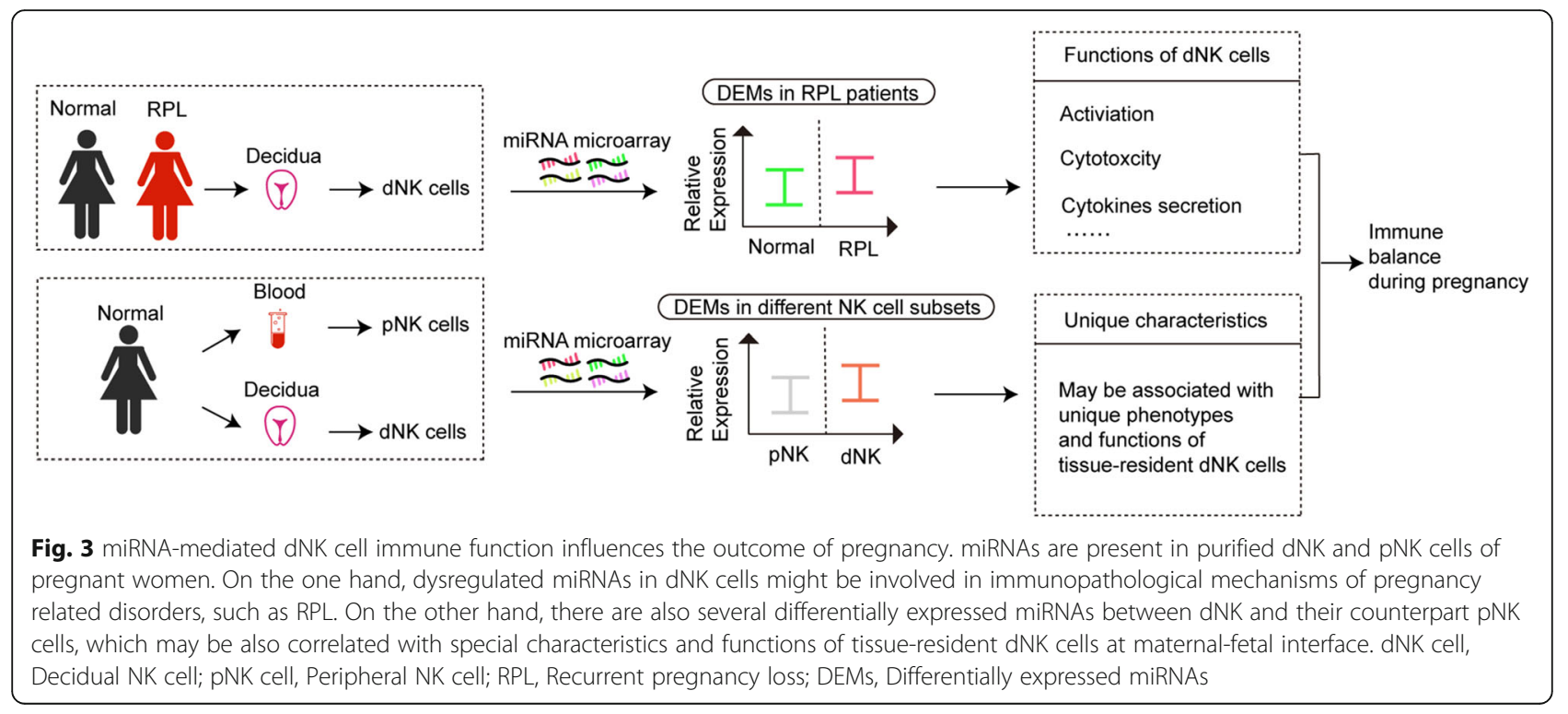


balance of pregnant women. In turn, NK cell-derived exosomes are identified to mediate cytotoxicity against tumor cells [96, 97], and it is not known whether dNK cell can secrete miRNA-containing exosomes or microvesicles into maternal-fetal interface, which can affect systemic inflammation, decidualization and biological behavior of other decidual cells.

\section{Concluding remarks}

We have highlighted the contributions of miRNAs in regulating the development and maturation of NK cells and also controlling the activation of NK cells and their subsequent actions such as generating pro- or anti-inflammatory factors during pregnancy. The dysregulations of miRNAs in both dNK cells and pNK cells could be involved in the immune regulations of pregnancy complications. Therefore, the NK cell-specific targeting of miRNA may present a novel strategy for the prevention and treatment of RPL. In addition, dNK cells exhibit a different miRNA expression pattern compared with their matched pNK cells during the first trimester of pregnancy. Notably, there are also differentially expressed miRNAs in pNK cells at different stages of pregnancy. We hypothesize that these differences may be related to the different numbers or unique functions of NK cells at each pregnancy stage, as well as certain resident characteristics of dNK cells. A more comprehensive understanding of the regulatory mechanisms of miRNAs in dNK and pNK cells and their functional specificities could set a new stage for balancing immune function and damage at the maternalfetal interface (Fig. 3).

\footnotetext{
Abbreviations

AGA: Appropriate-for-gestational-age; ANG: Angiopoietin; COVID19: Coronavirus disease 2019; CD: Cluster of differentiation; CXCR: C-X-C motif chemokine receptor; DEMs: Differentially Expressed miRNAs; dNK cell: Decidual NK cell; DSCs: Decidual stromal cells; ESCs: Endometrial stromal cells; EVT: Extra-villous trophoblast; FGR: Fetal growth retardation; GNLY: Granulysin; HCMV: Human cytomegalovirus; HGF: Hepatocyte growth factor; IL: Interleukin; IP: Interferon gamma-inducible protein; IFN: Interferon; miRNA: MicroRNA; NCR: Natural cytotoxicity receptor; PE: Pre-eclampsia; PGF: Placental growth factor; pNK cell: peripheral NK cell; PTHLH: Parathyroid hormone-like hormone; RPL: Recurrent pregnancy loss; SGA: Small-forgestational-age; TGF: Transforming growth factor; TNF: Tumor necrosis factor; Treg cell: Regulatory T cell; uNK: Uterine NK; VEGF: Vascular endothelial growth factor; VSMC: Vascular smooth muscle cell
}

\section{Authors' contributions}

H.L. and L.L. conceived and designed the study. L.L. wrote the manuscript. T.F., W.Z. and Y.L. provided a substantial contribution to discussion of content. All the authors have reviewed, commented, and edited the manuscript. The author(s) read and approved the final manuscript.

\section{Funding}

This work was financially supported by the National Natural Science Foundation of China (No. 81671497; No.81971461) and the research and development projects of Science and Technology Department of Sichuan Province (2019YJ0066)

\section{Availability of data and materials}

Literature research results are available from the authors upon reasonable request.

\section{Declarations}

Ethics approval and consent to participate

Not applicable.

\section{Consent for publication}

Not applicable.

\section{Competing interests}

The authors declare that they have no competing interests.

Received: 28 April 2021 Accepted: 27 July 2021

Published online: 02 October 2021

\section{References}

1. Negishi $Y$, Takahashi H, Kuwabara $Y$, Takeshita T. Innate immune cells in reproduction. J Obstet Gynaecol Res. 2018;44:2025-36.

2. Mor $G$, Aldo $P$, Alvero $A B$. The unique immunological and microbial aspects of pregnancy. Nat Rev Immunol. 2017;17:469-82.

3. Yang F, Zheng Q, Jin L. Dynamic Function and Composition Changes of Immune Cells During Normal and Pathological Pregnancy at the MaternalFetal Interface. Front Immunol. 2019;10:2317.

4. Vacca P, Chiossone L, Mingari MC, Moretta L. Heterogeneity of NK Cells and Other Innate Lymphoid Cells in Human and Murine Decidua. Front Immunol. 2019;10:170.

5. Jabrane-Ferrat N. Features of Human Decidual NK Cells in Healthy Pregnancy and During Viral Infection. Front Immunol. 2019;10:1397.

6. Jena MK, Nayak N, Chen K, Nayak NR. Role of Macrophages in Pregnancy and Related Complications. Arch Immunol Ther Exp (Warsz). 2019;67:295-309.

7. Gardner L, Moffett A. Dendritic cells in the human decidua. Biol Reprod. 2003;69:1438-46.

8. Taylor EB, Sasser JM. Natural killer cells and T lymphocytes in pregnancy and pre-eclampsia. Clin Sci (Lond). 2017;131:2911-7.

9. Yang SL, Tan HX, Niu TT, Li DJ, Wang HY, Li MQ. Kynurenine promotes the cytotoxicity of NK cells through aryl hydrocarbon receptor in early pregnancy. J Reprod Immunol. 2021;143:103270.

10. Strobel L, Vomstein K, Kyvelidou C, Hofer-Tollinger S, Feil K, Kuon RJ, Ebner S, Troppmair J, Toth B. Different background: natural killer cell profiles in secondary versus primary recurrent pregnancy loss. J Clin Med 2021;10.

11. Zhou Y, Fu B, Xu X, Zhang J, Tong X, Wang Y, Dong Z, Zhang X, Shen N, Zhai $Y$, et al: PBX1 expression in uterine natural killer cells drives fetal growth. Sci Transl Med 2020;12.

12. Fu B, Zhou Y, Ni X, Tong $X$, Xu X, Dong Z, Sun R, Tian Z, Wei H. Natural killer cells promote fetal development through the secretion of growthpromoting factors. Immunity. 2017:47:1100-13 e1106.

13. Bidarimath M, Khalaj K, Wessels JM, Tayade C. MicroRNAs, immune cells and pregnancy. Cell Mol Immunol. 2014;11:538-47.

14. Starkey PM, Sargent IL, Redman CW. Cell populations in human early pregnancy decidua: characterization and isolation of large granular lymphocytes by flow cytometry. Immunology. 1988;65:129-34.

15. Bulmer JN, Morrison L, Longfellow M, Ritson A, Pace D. Granulated lymphocytes in human endometrium: histochemical and immunohistochemical studies. Hum Reprod. 1991;6:791-8.

16. Sojka DK, Plougastel-Douglas B, Yang L, Pak-Wittel MA, Artyomov MN, Ivanova Y, Zhong C, Chase JM, Rothman PB, Yu J, et al. Tissue-resident natural killer (NK) cells are cell lineages distinct from thymic and conventional splenic NK cells. Elife. 2014;3:e01659.

17. Vacca P, Vitale C, Montaldo E, Conte R, Cantoni C, Fulcheri E, Darretta V, Moretta L, Mingari MC. CD34 + hematopoietic precursors are present in human decidua and differentiate into natural killer cells upon interaction with stromal cells. Proc Natl Acad Sci U S A. 2011;108:2402-7.

18. Cichocki F, Grzywacz B, Miller JS. Human NK cell development: one road or many? Front Immunol. 2019;10:2078.

19. Saito S, Nakashima A, Myojo-Higuma S, Shiozaki A. The balance between cytotoxic NK cells and regulatory NK cells in human pregnancy. J Reprod Immunol. 2008;77:14-22. 
20. Vento-Tormo R, Efremova M, Botting RA, Turco MY, Vento-Tormo M, Meyer KB, Park JE, Stephenson E, Polanski K, Goncalves A, et al. Single-cell reconstruction of the early maternal-fetal interface in humans. Nature. 2018; 563:347-53.

21. Wang XQ, Zhou WJ, Hou XX, Fu Q, Li DJ. Trophoblast-derived CXCL16 induces M2 macrophage polarization that in turn inactivates NK cells at the maternal-fetal interface. Cell Mol Immunol. 2018;15:1038-46.

22. Vacca P, Cantoni C, Vitale M, Prato C, Canegallo F, Fenoglio D, Ragni N, Moretta L, Mingari MC. Crosstalk between decidual NK and CD14 + myelomonocytic cells results in induction of Tregs and immunosuppression. Proc Natl Acad Sci U S A. 2010;107:11918-23.

23. Staff AC, Fjeldstad HE, Fosheim IK, Moe K, Turowski G, Johnsen GM, Alnaes-Katjavivi P, Sugulle M. Failure of physiological transformation and spiral artery atherosis: their roles in preeclampsia. Am J Obstet Gynecol 2020.

24. Robson A, Lash GE, Innes BA, Zhang JY, Robson SC, Bulmer JN. Uterine spiral artery muscle dedifferentiation. Hum Reprod. 2019;34:1428-38.

25. Soares MJ, Chakraborty D, Kubota K, Renaud SJ, Rumi MA. Adaptive mechanisms controlling uterine spiral artery remodeling during the establishment of pregnancy. Int J Dev Biol. 2014;58:247-59.

26. Lash GE, Robson SC, Bulmer JN. Review: Functional role of uterine natural killer (uNK) cells in human early pregnancy decidua. Placenta. 2010; 31(Suppl):87-92.

27. Wallace AE, Fraser R, Cartwright JE. Extravillous trophoblast and decidual natural killer cells: a remodelling partnership. Hum Reprod Update. 2012;18: 458-71.

28. Saito S, Nishikawa K, Morii T, Enomoto M, Narita N, Motoyoshi K, Ichijo M. Cytokine production by CD16-CD56bright natural killer cells in the human early pregnancy decidua. Int Immunol. 1993;5:559-63.

29. Liu W, Liu X, Luo M, Liu X, Luo Q, Tao H, Wu D, Lu S, Jin J, Zhao Y, Zou L. dNK derived IFN-gamma mediates VSMC migration and apoptosis via the induction of LncRNA MEG3: A role in uterovascular transformation. Placenta. 2017:50:32-9.

30. OTierney-Ginn PF, Lash GE. Beyond pregnancy: modulation of trophoblast invasion and its consequences for fetal growth and long-term children's health. J Reprod Immunol. 2014;104-105:37-42.

31. Ma Y, Liang X, Wu H, Zhang C, Ma Y. Long noncoding RNA NR_002794 is upregulated in preeclampsia and regulates the proliferation, apoptosis and invasion of trophoblast cells. Mol Med Rep. 2019;20:4567-75.

32. Zambuto SG, Clancy KBH, Harley BAC. Tuning trophoblast motility in a gelatin hydrogel via soluble cues from the maternal-fetal interface. Tissue Eng Part A. 2020;27:1064-73.

33. Hanna J, Goldman-Wohl D, Hamani Y, Avraham I, Greenfield C, NatansonYaron S, Prus D, Cohen-Daniel L, Arnon TI, Manaster I, et al. Decidual NK cells regulate key developmental processes at the human fetal-maternal interface. Nat Med. 2006;12:1065-74.

34. Ma L, Li G, Cao G, Zhu Y, Du MR, Zhao Y, Wang H, Liu Y, Yang Y, Li YX, et al. dNK cells facilitate the interaction between trophoblastic and endothelial cells via VEGF-C and HGF. Immunol Cell Biol. 2017;95:695-704.

35. Lin F, Yang C, Feng T, Yang S, Zhou R, Li H. The Maternal-Fetal Interface in Small-for-Gestational-Age Pregnancies Is Associated With a Reduced Quantity of Human Decidual NK Cells With Weaker Functional Ability. Front Cell Dev Biol. 2020;8:633.

36. Adams Waldorf KM, McAdams RM. Influence of infection during pregnancy on fetal development. Reproduction. 2013;146:R151-62

37. Siewiera J, El Costa H, Tabiasco J, Berrebi A, Cartron G, Le Bouteiller P, Jabrane-Ferrat N. Human cytomegalovirus infection elicits new decidual natural killer cell effector functions. PLoS Pathog. 2013;9:e1003257.

38. Crespo AC, Mulik S, Dotiwala F, Ansara JA, Sen Santara S, Ingersoll K, Ovies C, Junqueira C, Tilburgs T, Strominger JL, Lieberman J. Decidual NK Cells Transfer Granulysin to Selectively Kill Bacteria in Trophoblasts. Cell. 2020;182: 1125-39 e1118

39. Quillay H, El Costa H, Duriez M, Marlin R, Cannou C, Madec Y, de Truchis C, Rahmati M, Barre-Sinoussi F, Nugeyre MT, Menu E. NK cells control HIV-1 infection of macrophages through soluble factors and cellular contacts in the human decidua. Retrovirology. 2016;13:39.

40. Li R, Yin T, Fang F, Li Q, Chen J, Wang Y, Hao Y, Wu G, Duan P, Wang Y, et al. Potential risks of SARS-CoV-2 infection on reproductive health. Reprod Biomed Online. 2020;41:89-95.

41. Cha J, Sun X, Dey SK. Mechanisms of implantation: strategies for successful pregnancy. Nat Med. 2012;18:1754-67.
42. Lu H, Yang HL, Zhou WJ, Lai ZZ, Qiu XM, Fu Q, Zhao JY, Wang J, Li DJ, Li MQ. Rapamycin prevents spontaneous abortion by triggering decidual stromal cell autophagy-mediated NK cell residence. Autophagy 2020:1-17. Online ahead of print.

43. Sherafat-Kazemzadeh R, Schroeder JK, Kessler CA, Handwerger S. Parathyroid hormone-like hormone (PTHLH) represses decidualization of human uterine fibroblast cells by an autocrine/paracrine mechanism. J Clin Endocrinol Metab. 2011;96:509-14.

44. Salamonsen LA, Dimitriadis $\mathrm{E}$, Jones RL, Nie G. Complex regulation of decidualization: a role for cytokines and proteases-a review. Placenta. 2003; 24(Suppl A):76-85.

45. Yang HL, Zhou WJ, Lu H, Lei ST, Ha SY, Lai ZZ, Zheng ZM, Ruan LY, He YY, Li DJ, et al. Decidual stromal cells promote the differentiation of CD56(bright) CD16(-) NK cells by secreting IL-24 in early pregnancy. Am J Reprod Immunol. 2019;81:e13110.

46. Zhang Y, Wang Y, Wang XH, Zhou WJ, Jin LP, Li MQ. Crosstalk between human endometrial stromal cells and decidual NK cells promotes decidualization in vitro by upregulating IL25. Mol Med Rep. 2018;17:2869-78.

47. Treiber T, Treiber N, Meister G. Regulation of microRNA biogenesis and its crosstalk with other cellular pathways. Nat Rev Mol Cell Biol. 2019;20:5-20.

48. Mohapatra S, Pioppini C, Ozpolat B, Calin GA. Non-coding RNAs regulation of macrophage polarization in cancer. Mol Cancer. 2021;20:24.

49. Wang $X$, He Y, Mackowiak B, Gao B. MicroRNAs as regulators, biomarkers and therapeutic targets in liver diseases. Gut. 2020;70:784-95.

50. O'Brien K, Breyne K, Ughetto S, Laurent LC, Breakefield XO. RNA delivery by extracellular vesicles in mammalian cells and its applications. Nat Rev Mol Cell Biol. 2020;21:585-606.

51. Ishida Y, Zhao D, Ohkuchi A, Kuwata T, Yoshitake H, Yuge K, Takizawa T, Matsubara S, Suzuki M, Saito S, Takizawa T. Maternal peripheral blood natural killer cells incorporate placenta-associated microRNAs during pregnancy. Int J Mol Med. 2015;35:1511-24.

52. Kambe $S$, Yoshitake $H$, Yuge $K$, Ishida Y, Ali MM, Takizawa T, Kuwata T, Ohkuchi A, Matsubara S, Suzuki M, et al. Human exosomal placentaassociated miR-517a-3p modulates the expression of PRKG1 mRNA in Jurkat cells. Biol Reprod. 2014;91:129.

53. Carlino C, Rippo MR, Lazzarini R, Monsurro V, Morrone S, Angelini S, Trotta E, Stabile H, Bastianelli C, Albertini MC, et al. Differential microRNA expression between decidual and peripheral blood natural killer cells in early pregnancy. Hum Reprod. 2018;33:2184-95.

54. Geiger TL, Sun JC. Development and maturation of natural killer cells. Curr Opin Immunol. 2016;39:82-9.

55. Mehta A, Baltimore D. MicroRNAs as regulatory elements in immune system logic. Nat Rev Immunol. 2016;16:279-94.

56. Zhang Z, Qin H, Jiang B, Chen W, Cao W, Zhao X, Yuan H, Qi W, Zhuo D, Guo H: miR-30e-5p suppresses cell proliferation and migration in bladder cancer through regulating metadherin. J Cell Biochem. 2019;120:15924-32.

57. Zhang W, Chang H, Zhang H, Zhang L. MiR-30e Attenuates Isoproterenolinduced Cardiac Fibrosis Through Suppressing Snai1/TGF-beta Signaling. J Cardiovasc Pharmacol. 2017;70:362-8.

58. Liu MM, Li Z, Han XD, Shi JH, Tu DY, Song W, Zhang J, Qiu XL, Ren Y, Zhen LL. MiR-30e inhibits tumor growth and chemoresistance via targeting IRS1 in Breast Cancer. Sci Rep. 2017;7:15929.

59. Huang Q, Ding J, Gong M, Wei M, Zhao Q, Yang J. Effect of miR-30e regulating $N K$ cell activities on immune tolerance of maternal-fetal interface by targeting PRF1. Biomed Pharmacother. 2019;109:1478-87.

60. Barrow AD, Edeling MA, Trifonov V, Luo J, Goyal P, Bohl B, Bando JK, Kim AH, Walker J, Andahazy M, et al. Natural Killer Cells Control Tumor Growth by Sensing a Growth Factor. Cell. 2018;172:534-48 e519.

61. Horton NC, Mathew PA. NKp44 and Natural Cytotoxicity Receptors as Damage-Associated Molecular Pattern Recognition Receptors. Front Immunol. 2015;6:31.

62. Vacca P, Cantoni C, Prato C, Fulcheri E, Moretta A, Moretta L, Mingari MC. Regulatory role of NKp44, NKp46, DNAM-1 and NKG2D receptors in the interaction between NK cells and trophoblast cells. Evidence for divergent functional profiles of decidual versus peripheral NK cells. Int Immunol. 2008;20:1395-405.

63. Xue TY, He YZ, Zhang JJ, Zhang XY, Xin YJ, Lu Y, Li YH. KIR2DL1-HLA signaling pathway: notable inhibition in the cytotoxicity of allo-NK cell against KG1A cell. Clin Lab. 2013;59:613-9.

64. Kucuksezer UC, Aktas Cetin E, Esen F, Tahrali I, Akdeniz N, Gelmez MY, Deniz G. The Role of Natural Killer Cells in Autoimmune Diseases. Front Immunol. 2021;12:622306 
65. Lidstrom C, Matthiesen L, Berg G, Sharma S, Ernerudh J, Ekerfelt C. Cytokine secretion patterns of NK cells and macrophages in early human pregnancy decidua and blood: implications for suppressor macrophages in decidua. Am J Reprod Immunol. 2003;50:444-52.

66. Liu J, Dong P, Jia N, Wen X, Luo L, Wang S, Li J. The expression of intracellular cytokines of decidual natural killer cells in unexplained recurrent pregnancy loss. J Matern Fetal Neonatal Med. 2020;9:1-7.

67. Arjaans S, Wagner BD, Mourani PM, Mandell EW, Poindexter BB, Berger RMF, Abman SH. Early angiogenic proteins associated with high risk for bronchopulmonary dysplasia and pulmonary hypertension in preterm infants. Am J Physiol Lung Cell Mol Physiol. 2020;318:L644-54.

68. Gupta P, Deo S, Jaiswar SP, Sankhwar PL. Case Control Study to Compare Serum Vascular Endothelial Growth Factor (VEGF) Level in Women with Recurrent Pregnancy Loss (RPL) Compared to Women with Term Pregnancy. J Obstet Gynaecol India. 2019;69:95-102.

69. Ahmed A, Dunk C, Ahmad S, Khaliq A. Regulation of placental vascular endothelial growth factor (VEGF) and placenta growth factor (PIGF) and soluble Flt-1 by oxygen-a review. Placenta. 2000;21(Suppl A):16-24.

70. Anderson N, De Laat M, Benton S, von Dadelszen P, McCowan L. Placental growth factor as an indicator of fetal growth restriction in late-onset smallfor-gestational age pregnancies. Aust N Z J Obstet Gynaecol. 2019;59:89-95.

71. Li D, Li J. Association of miR-34a-3p/5p, miR-141-3p/5p, and miR-24 in Decidual Natural Killer Cells with Unexplained Recurrent Spontaneous Abortion. Med Sci Monit. 2016;22:922-9.

72. Li T, Cui L, Xu X, Zhang H, Jiang Y, Ren L, Yang C, Liu X, Hu X. The Role of Tim-3 on dNK Cells Dysfunction During Abnormal Pregnancy With Toxoplasma gondii Infection. Front Cell Infect Microbiol. 2021;11:587150.

73. Li D, Li J, Jia B, Wang Y, Zhang J, Liu G. Genome-wide identification of microRNAs in decidual natural killer cells from patients with unexplained recurrent spontaneous abortion. Am J Reprod Immunol. 2018;80:e13052.

74. Devor E, Santillan D, Scroggins S, Warrier A, Santillan M. Trimester-specific plasma exosome microRNA expression profiles in preeclampsia. J Matern Fetal Neonatal Med. 2020;33:3116-24.

75. Ali A, Hadlich F, Abbas MW, labal MA, Tesfaye D, Bouma GJ, Winger QA Ponsuksili S. MicroRNA-mRNA networks in pregnancy complications: a comprehensive downstream analysis of potential biomarkers. Int J Mol Sci. 2021;22:2313

76. Katano K, Suzuki S, Ozaki Y, Suzumori N, Kitaori T, Sugiura-Ogasawara M. Peripheral natural killer cell activity as a predictor of recurrent pregnancy loss: a large cohort study. Fertil Steril. 2013;100:1629-34.

77. Jairajpuri DS, Malalla ZH, Mahmood N, Khan F, Almawi WY. Differentially expressed circulating microRNAs associated with idiopathic recurrent pregnancy loss. Gene. 2021;768:145334.

78. Lee JY, Kim JO, Park HS, Ryu CS, Kim JH, Kim YR, Lee WS, Lee JR, Kim NK. Study of the Association Between microRNA (miR-25T > C, miR-32 C > A, miR-125 C > T, and miR-222G > T) Polymorphisms and the Risk of Recurrent Pregnancy Loss in Korean Women. Genes (Basel). 2020;11:354

79. Qu D, Tian X, Ding L, Li Y, Zhou W. Impacts of Cyclosporin A on clinical pregnancy outcomes of patients with a history of unexplained transfer failure: a retrospective cohort study. Reprod Biol Endocrinol. 2021;19:44.

80. Ali SB, Jeelall Y, Pennell CE, Hart R, McLean-Tooke A, Lucas M. The role of immunological testing and intervention in reproductive medicine: a fertile collaboration? Am J Reprod Immunol 2018;79.

81. Rupaimoole R, Slack FJ. MicroRNA therapeutics: towards a new era for the management of cancer and other diseases. Nat Rev Drug Discov. 2017;16: 203-22.

82. Catela Ivkovic T, Voss G, Cornella H, Ceder Y. microRNAs as cancer therapeutics: A step closer to clinical application. Cancer Lett. 2017:407:113-22.

83. Pelosi A, Alicata C, Tumino N, Ingegnere T, Loiacono F, Mingari MC, Moretta L, Vacca P. An Anti-inflammatory microRNA Signature Distinguishes Group 3 Innate Lymphoid Cells From Natural Killer Cells in Human Decidua. Front Immunol. 2020;11:133.

84. Tang L, Wei X, Li T, Chen Y, Dai Z, Lu C, Zheng G. Emerging Perspectives of RNA N (6)-methyladenosine (m(6)A) Modification on Immunity and Autoimmune Diseases. Front Immunol. 2021;12:630358

85. Tsiouplis NJ, Bailey DW, Chiou LF, Wissink FJ, Tsagaratou A. TET-Mediated Epigenetic Regulation in Immune Cell Development and Disease. Front Cell Dev Biol. 2020;8:623948.

86. Hu LL, Qian K, Li HX, Sun YP, Zhu GJ. [MicroRNA expression and its role in the cell cycle regulation in decidualized endometrial stromal cells in vitro]. Zhonghua Fu Chan Ke Za Zhi. 2012;47:129-33.
87. Soni UK, Chadchan SB, Gupta RK, Kumar V, Jha RK. miRNA-149 targets PARP2 in endometrial epithelial and stromal cells to regulate the trophoblast attachment process. Mol Hum Reprod. 2021;27:gaab039.

88. Zhang $Q$, Zhang $H$, Jiang Y, Xue B, Diao Z, Ding L, Zhen X, Sun H, Yan G, Hu $Y$. MicroRNA-181a is involved in the regulation of human endometrial stromal cell decidualization by inhibiting Kruppel-like factor 12. Reprod Biol Endocrinol. 2015;13:23.

89. Yan Q, Yan G, Zhang C, Wang Z, Huang C, Wang J, Zhou J, Liu Y, Ding L, Zhang Q, et al. miR-21 reverses impaired decidualization through modulation of KLF12 and NR4A1 expression in human endometrial stromal cellsdagger. Biol Reprod. 2019:100:1395-405.

90. Qu X, Fang Y, Zhuang S, Zhang Y. Micro-RNA miR-542-3p suppresses decidualization by targeting ILK pathways in human endometrial stromal cells. Sci Rep. 2021;11:7186.

91. Wang R, Zou L, Yang X. microRNA-210/ Long non-coding RNA MEG3 axis inhibits trophoblast cell migration and invasion by suppressing EMT process. Placenta. 2021;109:64-71.

92. Chu X, Gu Y, Sheng W, Sun J, Morgan JA, Lewis DF, Cooper DB, McCathran CE, Wang Y. Downregulation of miR-126-3p expression contributes to increased inflammatory response in placental trophoblasts in preeclampsia. J Reprod Immunol. 2021;144:103281.

93. Fan Y, Dong Z, Zhou G, Fu J, Zhan L, Gao M, Zhu L, Zhang Y. Elevated miR23a impairs trophoblast migration and invasiveness through HDAC2 inhibition and NF-kappaB activation. Life Sci. 2020;261:118358.

94. Ying $X$, Jin $X$, Zhu $Y$, Liang $M$, Chang $X$, Zheng $L$. Exosomes released from decidual macrophages deliver miR-153-3p, which inhibits trophoblastic biological behavior in unexplained recurrent spontaneous abortion. Int Immunopharmacol. 2020;88:106981.

95. Bidarimath $M$, Lingegowda H, Miller JE, Koti M, Tayade C. Insights Into Extracellular Vesicle/Exosome and miRNA Mediated Bi-Directional Communication During Porcine Pregnancy. Front Vet Sci. 2021;8:654064.

96. Kang YT, Niu Z, Hadlock T, Purcell E, Lo TW, Zeinali M, Owen S, Keshamouni VG, Reddy R, Ramnath N, Nagrath S. On-Chip Biogenesis of Circulating NK Cell-Derived Exosomes in Non-Small Cell Lung Cancer Exhibits Antitumoral Activity. Adv Sci (Weinh). 2021;8:2003747.

97. Di Pace AL, Tumino N, Besi F, Alicata C, Conti LA, Munari E, Maggi E, Vacca P. Moretta L. Characterization of Human NK Cell-Derived Exosomes: Role of DNAM1 Receptor In Exosome-Mediated Cytotoxicity Against Tumor. Cancers (Basel). 2020;12:661.

\section{Publisher's Note}

Springer Nature remains neutral with regard to jurisdictional claims in published maps and institutional affiliations.

Ready to submit your research? Choose BMC and benefit from:

- fast, convenient online submission

- thorough peer review by experienced researchers in your field

- rapid publication on acceptance

- support for research data, including large and complex data types

- gold Open Access which fosters wider collaboration and increased citations

- maximum visibility for your research: over $100 \mathrm{M}$ website views per year

At $\mathrm{BMC}$, research is always in progress.

Learn more biomedcentral.com/submissions 